\title{
Educational Affordances of a Facebook Group Page: A User Survey of Hong Kong Undergraduate Students
}

\author{
Emil Li \\ Graduate School of Education, Faculty of Social Sciences and Law \\ University of Bristol, Bristol, United Kingdom
}

Received: May 13, 2021

Accepted: July 24, $2021 \quad$ Published: August 1, 2021

doi:10.5296/jse.v11i3.18874 URL: https://doi.org/10.5296/jse.v11i3.18874

\begin{abstract}
Employing a mixed method approach, this exploratory research study provides an account of the educational affordances derived from the use of a Facebook group for out-of-class, off-campus learning by undergraduate students enrolled at a private university in Hong Kong. Both quantitative and qualitative results indicate that social networking sites such as Facebook can indeed be exploited to generate various educational affordances favorable to off-campus informal learning and course management activities in the context of higher education in Hong Kong.
\end{abstract}

Keywords: Affordances, Facebook, Web 2.0., Higher Education, Social Media 


\section{Introduction}

Facebook (Note 1), which was initially designed for social networking purposes, raises interesting possibilities for teaching and learning. This research study provides an exploratory account of the educational affordances derived from the use of a Facebook group for out-of-class, off-campus learning by undergraduate students enrolled at a private university in Hong Kong. This paper is structured as follows: Section 1 gives an introduction to this study; Section 2 lays out a brief review of current literature addressing both empirical and theoretical aspects of the use of web and mobile technologies in the higher education context, the educational values of Facebook as a teaching and learning platform for university students, and the theory of affordances; Section 3 provides background for the present study, descriptions of the research design, and procedures of data collection together with specific research questions; Sections 4 and 5 depict research findings and analyses respectively; and finally, Section 6 draws some conclusions and outlines recommendations for further empirical examination. It is hoped that this study has shed light on technologically innovative directions for the learning of digital natives using Facebook.

\section{Literature Review}

Before outlining the research design and findings of the present study, a brief review of major academic literature on three related areas, namely, (1) Web 2.0 and Mobile 2.0, (2) Use of Facebook in Higher Education, and (3) Theory of Affordances, is provided in the following sub-sections.

\subsection{Web 2.0 and Mobile 2.0}

Web1.0 refers to an early stage of the World Wide Web where most users acted as consumers of top-down, one-to-many display of content, whereas Web 2.0, the latest web-based technologies, has transformed web users from mere consumers to authors, producers and managers of bottom-up, many-with-many display of information on homepages (O'Reilly, 2005; Krishnamurthy \& Cormode, 2008; Dohn, 2009), which (1) enables social interactions (e.g. Facebook); (2) connects individuals with shared interests (e.g. Linked-in); (3) forms virtual communities (e.g. Twitter); and (4) contributes artefacts such as text (e.g. Wikipedia), photos (e.g. Picasa) and videos (e.g. YouTube). The transformation of web-based technologies from 1.0 to 2.0 has redefined the education realm in which Web 2.0 tools such as Facebook are providing appealing ways for teaching and learning in a participatory, interactive and collaborative manner.

In recent years, Mobile 2.0, which has evolved from mobile learning and Web 2.0 through the adaptation of web to mobile technologies including $4 \mathrm{G}$ and $\mathrm{Wi}-\mathrm{Fi}$, has created unprecedented teaching and learning opportunities (Copola et al, 2008). Mobile 2.0 and Web 2.0 are made compatible so that web-based technologies can be integrated, formatted and accessed in a wireless-enabled mobile digital device such as smartphones and tablets (Copola et al, 2008). As such, Mobile 2.0 and Web 2.0 technologies continuously fuel the rapid growth of new fields of research in the education sector. Research studies have found that Mobile 2.0 and 
Web 2.0 have great potential to support learning in an authentic environment in any context, dissolving boundaries between formal learning and social spaces, regardless of time and space constraints (Waycott \& Kennedy, 2009; Matias \& Wolf, 2013). This new way of teaching and learning using socially-based web tools in a mobile gadget has been termed "Pedagogy 2.0" (McLoughlin \& Lee, 2008), which features six interrelated aspects/dimensions, namely (1) Participatory Web, (2) Open Web, (3) Collaboration, (4) Sociability, (5) Open Classroom, and (6) Web as a Learning Platform (Jimoyiannis et al, 2013).

\subsection{Use of Facebook in Higher Education}

In recent years, research data have indicated that the use of Facebook for academic purposes has been gaining worldwide momentum in the higher education arena both for its merits and drawbacks in teaching and learning (Selwyn, 2007; Cain, 2008; Tomai et al, 2010; Vivian, 2011; Jackson, 2011; Junco, 2012; Wodzicki et al, 2012). This is because of the fact that the accessible feature of Facebook via mobile technologies lends itself to the nomadic lifestyle of today's university students who juggle their study, work and social life (Barkhuus \& Tashiro, 2010). Born into a world of digital technologies, the post 90's student is described as "tech-savvy" (Vivian \& Barnes, 2010) or "digital native" (Bennett et al, 2008). For instance, most college or university students surveyed in western English-speaking countries including the United States, the United Kingdom, Canada and Australia are heavily immersed themselves in SNSs, especially Twitter, Wiki, Weblog, YouTube and Facebook (Cain, 2008; Vivian, 2011; Madge et al, 2009). Sub-sections 2.2.1 and 2.2.2 draw from current empirical studies to outline the pros and cons of using Facebook for teaching and learning.

\subsection{Advantages of Using Facebook in Education}

Undergraduate students generally prefer using Facebook as a learning management system (LMS) to those provided by the university such as WebCT, Blackboard or Moodle simply due to the pre-existing familiarity and positive user experience (Kosik, 2007; Selwyn, 2007; Stutzman, 2008). Moreover, educators can potentially harness Facebook to create a communicative, interactive and supportive environment for today's tertiary students (Bosch, 2009; Mehdinezhad, 2011). There are also findings of virtual ethnographic studies which claim that Facebook is an effective and efficient platform for out-of-class, off-campus informal learning, offering a gateway to a virtual space whereby the student community can engage in more complex learning activities by communicating, collaborating, circulating, creating, and even competing in an interconnected way (Selwyn, 2007; Schwier, 2010; Vivian \& Barnes, 2010; Wodzicki et al, 2012). Another valued element that should be acknowledged is that many of the students investigated feel emotionally-connected, affectively-encouraged and highly-motivated when they participate in online discussions via Facebook while they usually feel shy, nervous or intimidated in the physical presence of others during in-class group activities (Tomai et al, 2010; Jackson, 2011; Wodzicki et al, 2012).

\subsection{Disadvantages of Using Facebook in Education}

Nevertheless, the educational value of SNSs has never gone uncontested and challenges arise 
whenever social media is to be incorporated into student learning. For instance, immature students may be easily distracted by excessive visual simulation which would have a negative impact on their academic performance (Junco, 2012). Besides, some researchers assert that educators should not overly intrude into the social space of students who may feel anxious, uncomfortable, or suspicious of interacting with their instructors or professors (Selwyn, 2007). Dohn (2009) raises concerns over the pedagogical challenges of SNS practices regarding the role of collaboration in learning, evaluation criteria, and the general objective and status of the material produced by student users. There are also privacy, security and legal issues that should be addressed appropriately (Barkhuus \& Tashiro, 2010).

In short, Facebook seems to be a double-edged sword. The ubiquitous use of Facebook on mobile devices among university students makes it a welcoming platform for learning and thus raises certain interrelated questions concerning positive and negative educational affordances. Therefore, this paper aims to explore and report findings in respect to Hong Kong tertiary students vis-à-vis their perceptions of possible educational affordances with Facebook.

\subsection{Theory of Affordances}

The use of social networking tools such as Facebook seems to have spread to a wide range of contexts thanks to the opportunities they offer for redefining many playing fields and opening up the possibilities of linking different individuals regardless of time and space boundaries. The increasing adoption of Facebook in education settings makes it relevant to explore what exactly it can afford. The concept of affordances was originally developed by James Gibson, who has taken an ecological and psychological angle to interpret human cognition and actions in relation to the surrounding environment. He argues that the identification of affordances can be used to look into what drives a person to adopt and make use of the properties of a particular object (Gibson, 1979). However, Gibson's conceptualisation of affordances only embraces a purely natural vision of an environment, while it fails to consider the social and cultural ways of perceiving such an environment.

Later, Norman (1999) suggested an alternative to the Gibsonian theory of affordances by stating that it is important to recognise the intended affordances of a designed technological artefact (i.e. real affordances) and its unintended affordances which are perceived by the user (i.e. perceived affordances). Norman's notion of technological affordances which takes into account of the relationship between humans, technologies and implications for technology use, has since become popularised in the paradigm of human-computer interaction. Recently, in their investigation on the use of social media, Treem and Leonardi (2012:36) exemplified the ways that technologies can be used to adopt a set of specially designated affordances based on the perspectives the users have.

Later still, Bloomfield, Latham and Vurdubakis redefined and renamed Norman's notion as "Situated Technological Affordances" (2010:416). In association with the socio-historical background, the human body and the material itself, an affordance cannot be separated from the arrangements through which it is produced in practice. Therefore, affordances will only emerge in a specific context at a specific time within a specific sociocultural setting, and thus 
cannot be discovered or encountered randomly (Bloomfield et al, 2010).

In sum, an affordance perceived and enacted in a specific socio-cultural situation by a given person is relatively dependent on the skills and knowledge this person acquired in his/her past experience. The rise of Facebook as a social networking tool has created a new education platform for educators and those they teach nowadays, and thus this research paper aims to identify what specific affordances a Facebook group offers to its student users. As the literature on the above three areas is fast growing, this is by no means an exhaustive literature review but merely an overview to give a sense of the direction this research study takes. This research paper aims to investigate what a Facebook group can afford in terms of student learning and course management through the lens of Bloomfield's theory of Situated Technological Affordances.

\section{Research Design}

\subsection{Research Background}

A substantial amount of data supports the fact that user familiarity and preference for using Facebook over other formal e-platforms have played an important role in off-campus informal learning. Today's Hong Kong university students, digitally conversant and surrounded by an array of cutting-edge gadgets which permit easy access to the latest web and mobile technologies, log on to their Facebook accounts anytime and anywhere. The present study attempts to look into students' perceptual reasoning behind them choosing to manage learning via Facebook rather than Moodle, an official LMS provided by the university.

\subsection{Research Sample}

A Facebook group for a class of students taking a bridging language course named "Chinese 101 " was set up at the beginning of the summer semester in the current Academic Year. The participating students were drawn from a class of 25 local first-year undergraduate students (20 females and 5 males) majoring in health care at a self-financed tertiary institute in Hong Kong.

\subsection{Research Questions}

The purpose of this research study was to identify the educational affordances of using a Facebook group for learning in the higher education context of Hong Kong. Therefore, three research questions were developed.

1. What are the attitudes of Hong Kong private university students towards the use of Facebook in an academic setting?

2. How are the specific educational affordances of a Facebook group generally perceived by its university student users?

3. To what extent would university student users think a Facebook group is effective or ineffective when it is used to support their learning and course management activities? 


\subsection{Research Methodology}

Learning is known to be a complex and confounding process, so it is not easy to measure learning either quantitatively or qualitatively; rather it may be mutually complementary to adopt a mixed-method approach which include both quantitative and qualitative components. Because of the need to measure and explore insights about the real-life experience of using Facebook for learning from the targeted students, both quantitative and qualitative research methods are applied for this study, with the former yielding statistical, mathematical or numerical data (e.g. frequency, scale, preference, etc.) and the latter eliciting participants' responses (e.g. opinions, feelings, attitudes, behaviours) towards the research questions. A questionnaire survey was administered to the targeted students before the course, while a face-to-face, semi-structured group interview was conducted after the course. The following sub-sections provide a detailed description of the research methods employed in this study.

\subsubsection{Questionnaire}

A total number of 9 closed-ended questions was set for the questionnaire survey. Using this quantitative method allowed the researcher to collect mass information from a group of targeted subjects, which is useful for generating numerical data for easy comparison. Because of the lack of personal interaction, questionnaires generally elicit honest responses. A pilot test was conducted with 3 volunteer students in order to check if the questionnaire was worded clearly and if it was visually appealing and appropriate to the targeted respondents. Refining was undertaken after the pilot test so as to capture a more accurate picture of a situation.

\subsubsection{Interview}

Two students with high use rate of Facebook during the course were selected to participate a semi-structured, face-to-face, in-depth interview, which allowed the researcher to probe into embedded meanings and to observe the manner as well as the intonation of interviewees' responses to better understand their constructed reality and interpret their experience with Facebook. The medium of interview was Cantonese, the mother language of the interviewees. A set of interview questions together with a cover letter stating the purpose of the present research study and emphasising confidentiality and anonymity, was sent via email to the participants three days before the scheduled interview date in order to allow some time for them to reflect and prepare for the actual interview, which took approximately 15 minutes at a campus cafe. In order to facilitate the identification of patterns and the sorting of categories, the whole interview process was audiotaped, prior to consent having been obtained from the participating students. An interview note was then transcribed and sent back to them for verification and confirmation of their respective accounts.

\subsection{Data Collection and Analysis}

Data were collected by using different instruments. The data gathered via completed questionnaires were carefully read through, analytically interpreted and statistically described for later presentation, while information elicited from the 15-minute interview formed the basis of subsequent interpretative analysis. The responses from the interview were 
tape-recorded and transcribed into a verbatim format for later coding by which common themes and salient comments were identified and analysed without compromising anonymity. For ethical consideration, participation in this study was entirely on a voluntary basis. Participating students were also well informed about the purpose of this study. Anonymity in terms of individual respondents is highly respected as the research project has not collected any identifiable information of individual subjects such as names, mobile numbers and email addresses and the research paper has not linked individual responses with the identities of the interviewees.

\subsection{Facebook Group Setup}

The bridging course Chinese 1 was chosen for this particular research study. The course instructor used his personal Facebook account to open a Facebook group named "Chinese 1 Health Care" and students enrolled in this course were invited to join the group. For privacy and security purposes, this Facebook group was set as a closed group to avoid public access to the content by non-members.

\section{Findings}

\subsection{Quantitative Results}

The questionnaire survey was administered to a class of 25 students doing the Bachelor Degree of Science in Health Care before their Chinese 101 course began. The following tables present the data resulting from the quantitative survey. Q1, 2, 7, 8 \& 9 are dichotomous questions where two options (either yes or no) are given for the respondents to choose.

Table 1 shows a detailed breakdown of the results of each dichotomous question.

\begin{tabular}{|l|c|c|c|c|c|c|}
\hline \multirow{2}{*}{ Question } & \multicolumn{2}{|c|}{ Yes } & \multicolumn{2}{c|}{ No } & \multicolumn{2}{c|}{ Total } \\
\cline { 2 - 7 } & $\#$ & $\mathbf{\%}$ & $\#$ & $\mathbf{\%}$ & $\#$ & $\mathbf{\%}$ \\
\hline Q1:Possession of a Facebook Account & 25 & $100 \%$ & 0 & $0 \%$ & $\underline{\underline{25}}$ & $\underline{\underline{100}}$ \\
\hline Q2:Using Facebook Before Studying in University & 21 & $84 \%$ & 4 & $16 \%$ & $\underline{\underline{25}}$ & $\underline{\underline{100}}$ \\
\hline Q7:Likelihood of Communicating with the Instructor via Facebook & 19 & $76 \%$ & 6 & $24 \%$ & $\underline{\underline{\underline{25}}}$ & $\underline{\underline{100}}$ \\
\hline Q8:Likelihood of Assisting Learning by Facebook & 15 & $60 \%$ & 10 & $40 \%$ & $\underline{\underline{\underline{25}}}$ & $\underline{\underline{\underline{100}}}$ \\
\hline Q9:Likelihood of Enhancing Academic Life via Facebook & 20 & $80 \%$ & 5 & $20 \%$ & $\underline{\underline{\underline{25}}}$ & $\underline{\underline{100}}$ \\
\hline
\end{tabular}

Table 1: Results of Dichotomous Questions 1, 2, 7, 8 \& 9

\section{Q3: Frequency of Using Facebook per Day}

Table 2 displays the frequency with which account holders use Facebook on a daily basis. As expected, $80 \%$ of the 25 students were heavy users in that they checked their Facebook posts either extremely often or very often, whereas $12 \%$ of them were fairly often users and only $8 \%$ of them less often users. None of the respondents had hardly ever used Facebook before. 


\begin{tabular}{|ccc|}
\hline Frequency & No. of Respondents & Percentage (\%) \\
\cline { 2 - 3 } extremely often & 9 & $36 \%$ \\
very often & 11 & $44 \%$ \\
fairly often & 3 & $12 \%$ \\
less often & 2 & $8 \%$ \\
hardly ever & 0 & $0 \%$ \\
Total & $\underline{\underline{\mathbf{2 5}}}$ & $\underline{\underline{100}}$ \\
\hline
\end{tabular}

Table 2: Frequency of Using Facebook per Day

\section{Q4: Major Reasons for Using Facebook}

For this question, the students were required to choose one major reason for using Facebook from a selection of 6 choices provided. Table 3 indicates that the three main reasons for using Facebook in descending order are "Quick Sharing" (28\%), "Easy Communication" (24\%) and "Trendy" (24\%). When considering why to open a Facebook account, 16\% of the students opted for "Free of Charge", whereas only $8 \%$ ticked "Making New Friends".

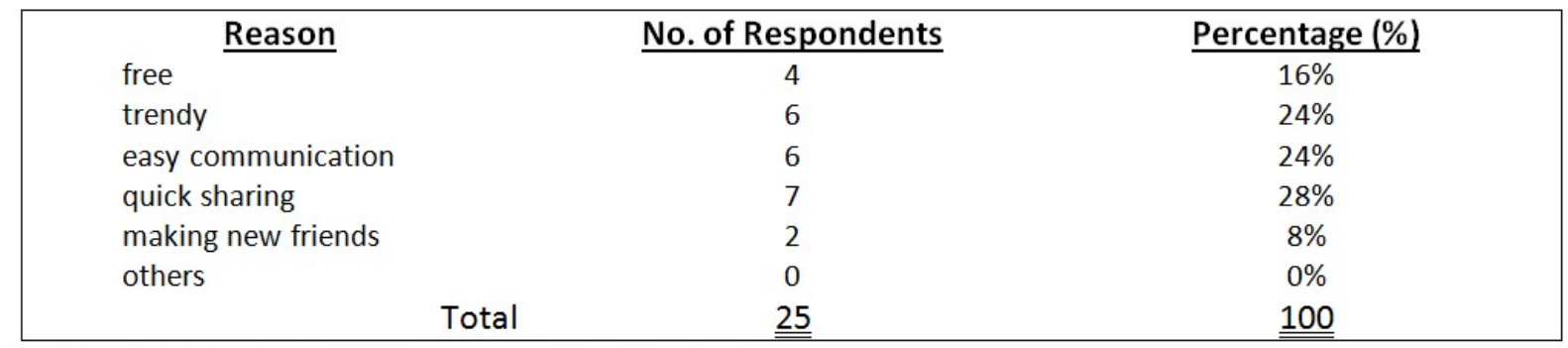

Table 3: Major Reasons for Using Facebook

\section{Q5: Frequency of Using Moodle per Day}

The students were also asked if they used Moodle, the LMS tool provided by the University, on a daily basis. The results in Table 4 reveal that only one student used Moodle very often, and half of the students (52\%) used it fairly often. Surprisingly, $28 \%$ of them hardly ever used Moodle to manage their course activities at all.

\begin{tabular}{|c|c|c|}
\hline Frequency & No. of Respondents & Percentage (\%) \\
\hline extremely often & 0 & $0 \%$ \\
\hline very often & 1 & $4 \%$ \\
\hline fairly often & 13 & $52 \%$ \\
\hline less often & 4 & $16 \%$ \\
\hline hardly ever & 7 & $28 \%$ \\
\hline Total & $\underline{25}$ & $\underline{100}$ \\
\hline
\end{tabular}

Table 4: Frequency of Using Moodle per Day

\section{Q6: Preference for Facebook over Moodle}

Of the 25 students who responded to the questionnaire survey, the majority (88\%) would like to try using Facebook for learning and course management activities, and only three $(12 \%)$ rejected the idea and would stick to Moodle (see Table 5). 


\begin{tabular}{|cccc|}
\hline Answer & & No. of Respondents & Percentage (\%) \\
\cline { 2 - 4 } Facebook & 22 & $88 \%$ \\
Moodle & 3 & $12 \%$ \\
& Total & $\underline{\underline{25}}$ & $\underline{\underline{100}}$ \\
\hline
\end{tabular}

Table 5: Preference for Facebook over Moodle

\subsection{Qualitative Results}

For the purpose of illustration, an extract from an interview with two students has been documented. Table 6 below shows 5 major categories emerging from the content analysis of students' interview responses of their overall experience of using a Facebook group during the course.

\begin{tabular}{|l|l|}
\hline \multicolumn{1}{|c|}{ Categories } & \multicolumn{1}{c|}{ Associated Words/Phrases } \\
\hline Database & uploaded, saved, revisit, resources \\
\hline Noticeboard & $\begin{array}{l}\text { notified, browse, discuss, discussion, notice, } \\
\text { post announcements }\end{array}$ \\
\hline Monitor & catch, trace and track, poke, remind \\
\hline Organiser & $\begin{array}{l}\text { meet, group projects, arrange work, manage } \\
\text { our study, binds us together, }\end{array}$ \\
\hline Platform for Academic Activities & $\begin{array}{l}\text { comments, ideas, talk to, communicate, ask a } \\
\text { question, share anything }\end{array}$ \\
\hline
\end{tabular}

Table 6: Five Major Categories Emerging from Students' Interview Responses

\section{Analysis and Discussion}

\subsection{Analysis of \& Discussion on the Quantitative Results}

The data provided by the pre-course questionnaire survey demonstrate consistencies with the literature on the use of Facebook by university students in Section 2. On the whole, of the 25 surveyed students, all have been using their Facebook accounts prior to entering university and most of them check the site constantly throughout the day. It appears that these students are habitual Facebook users. The on-the-go accessible nature of Facebook has perhaps lent itself to the lifestyle of university students who have the technological ability to network with their peers anytime and anywhere via a mobile device. Factors that influence their decision to choose Facebook over Moodle as an LMS include Facebook being familiar and trendy. Many of the students believe that there are potential benefits of using Facebook for their learning and academic life. They also show openness and willingness to making contact with their teachers via Facebook, possibly due to the relaxing and comfortable social space it offers. It can be inferred that if university students become closer to their instructors by opening up informal and personal communication channels in a non-traditional classroom environment, they are more likely to be drawn to the course and thereby more easily achieve their learning outcomes. This aligns with the Confucian education philosophy of "a friend-like mentorship". Based on the quantitative evidence gathered, the researcher was motivated to open a teacher-initiated Facebook group aiming to find out what Facebook can afford in terms of learning and course management for university student users. 


\subsection{Analysis of \& Discussion on the Qualitative Results}

In line with Bloomfield's theory of Situated Technological Affordances, the primary purpose of this study is to explore how and what a Facebook group can afford for learning and course management based on student users' perceptions and their first-hand experience. The qualitative evidence shows that the use of a Facebook group by the participating students in this exploratory research has resulted in 5 situated educational affordances (see Table 7). The following paragraphs explain each of them in detail.

\section{Database}

The interviewed students created an alternative way to present a PowerPoint lecture handout as a photo album in the Facebook group. The teaching content in each ppt slide was converted into a sequence of jpg images and stored in a photo album for mass discussion. Whenever they had questions regarding the content on a particular photo (in the form of a PowerPoint slide), they would leave comments in an attempt to clarify their understanding or to negotiate meanings with other group members. A learning record would then be created and saved permanently in the Facebook group for subsequent retrieval and review. The students claimed that the Facebook group had provided a useful database for uploading and downloading course-related learning resources in multiple formats, which could be stored and accessed at their convenience.

\section{Noticeboard}

The interviewed students turned the Wall function into a noticeboard which could update them regularly on course activities and any sudden changes. They also highlighted the fact that both teachers and their fellow students often did micromanagement of course logistics such as putting up announcements on change of teaching venues, class cancellation, etc. They preferred using this to their university email accounts.

\section{Monitor}

It was found that the students could monitor the participation and contribution of their group members as the name of an individual was shown on the page automatically to indicate $\mathrm{s} / \mathrm{he}$ had read the post. A time stamp was also made to record when and at what time a particular student had created a post, allocated resources or shared comments. This allowed fair assessment of individual contribution by every group member. Since all post entries are attached with a time record in reverse chronologically order, it is suggested that the course instructor can make use of this affordance to check and identify the learning progress and process of the whole class so that teaching strategies can be adjusted accordingly.

\section{Organiser}

The students expressed that it was easy for them to schedule group meetings for discussing assessment items on the Event page by filling in the event name, details, location and time, and then inviting their group members to join. As university students in Hong Kong become more embedded in their academic life, Facebook is increasingly used for organising group meetings for projects, exam revision and coursework queries. This affordance enabled them 
to coordinate their collaborative effort.

\section{Platform for Academic Activities}

A Facebook group provided a helpful platform for students to extend academic activities with their peers and teachers outside the classroom. Whenever there were updates to the group page, instant text messages were sent automatically to the mobile device of all Facebook users so that they could access those new changes, engage in discussion and leave comments. The student participants particularly liked this platform because they could be informed and reminded immediately of any updates and therefore obtained peer feedback instantly. Since Facebook provides a friendly and comfortable social space for users to interact with each other, this can be transferred to a virtual academic space where students would feel less pressured to engage in discussion and are likely to seek assistance from their classmates and instructors. This way, Facebook could reduce the traditional power hierarchy between active students and those who are passive in class as well as between students and teachers, thus fostering a more emancipating and motivational climate that is conducive to learning. These students regarded the Facebook group as "cyber glue" that created a dynamic course and a sense of belonging.

\begin{tabular}{|c|c|c|}
\hline \multicolumn{3}{|c|}{ Affordances of a Facebook Group } \\
\hline & $\begin{array}{l}\text { Real Affordances } \\
\text { (Social) }\end{array}$ & $\begin{array}{c}\text { Situated Affordances } \\
\text { (Educational) }\end{array}$ \\
\hline 1. & $\begin{array}{l}\text { Storage of social life } \\
\text { - Photo Albums } \\
\text { - Videos } \\
\text { - Hyperlinks }\end{array}$ & $\begin{array}{l}\text { Database } \\
\text { Functions: } \\
\text { - Store lecture notes in Doc/PPT/PDF } \\
\text { formats } \\
\text { - Keep reference materials in stock } \\
\text { Features: } \\
\text { - Retrievable } \\
\text { - Assessable } \\
\text { - Permanent } \\
\text { - Chronological sequencing }\end{array}$ \\
\hline 2. & $\begin{array}{ll}\text { Wall } & \\
\text { - } & \text { Keep updated with social life } \\
& \text { events } \\
\text { - } & \text { Stay tuned with friends } \\
\text { - } & \text { Share personal feelings }\end{array}$ & $\begin{array}{l}\text { Noticeboard } \\
\text { Functions: } \\
\text { - Post announcements } \\
\text { - Manage course-related administrative } \\
\text { arrangements } \\
\text { Features: } \\
\text { - Instant } \\
\text { - Asynchronous \& Synchronous }\end{array}$ \\
\hline 3. & $\begin{array}{l}\text { Time Stamp } \\
\text { - Show last online time }\end{array}$ & $\begin{array}{l}\text { Monitor } \\
\text { Functions: } \\
\text { - Show evidence of individual } \\
\text { contribution } \\
\text { - Keep records of individual participation }\end{array}$ \\
\hline
\end{tabular}




\begin{tabular}{|c|c|c|}
\hline & & $\begin{array}{l}\text { Features: } \\
\text { • Traceable }\end{array}$ \\
\hline 4. & $\begin{array}{c}\text { Event } \\
\text { - Schedule social activities } \\
\text { - Organise social gathering }\end{array}$ & $\begin{array}{l}\text { Organiser } \\
\text { Functions: } \\
\text { - Schedule meetings for projects } \\
\text { - Form study groups } \\
\text { - Hold exam revision sessions } \\
\text { Features: } \\
\text { - Convenient } \\
\text { - Private }\end{array}$ \\
\hline 5. & $\begin{array}{l}\text { Discussion Thread } \\
\text { - Create a chain of written ideas or } \\
\text { opinions } \\
\text { - Follow through the entire } \\
\text { discussion from the very } \\
\text { beginning to the latest }\end{array}$ & $\begin{array}{l}\text { Platform for Academic Activities } \\
\text { Functions: } \\
\text { - Give ideas, comments and feedback } \\
\text { - Clarify concepts and understandings } \\
\text { - Ask and answer questions on } \\
\text { assessment details } \\
\text { Features: } \\
\text { - Editable } \\
\text { - Recordable }\end{array}$ \\
\hline
\end{tabular}

Table 7: Five Educational Affordances of a Facebook Group

As voiced by two students, Facebook was a hindrance at times, but they still perceived it to be valuable technology for off-campus informal learning and believed the benefits could outweigh the negative aspects. In all, a clear picture is emerging with the interviewed students opting for a Facebook group as an LMS for learning and managing course matters. The qualitative findings of the study support the quantitative data in that the participating students perceive the use of a Facebook group positively. It has obviously become more than just a social networking site for some students and has served the function of an informal LMS.

\section{Conclusion}

This study faces one noticeable limitation which is the generalisability of the sample. Where this paper refers to "university students", it actually refers to those 25 students within one focus group of this research. The researcher recognises that generalisations cannot be fully made based on the small number of participants. The views expressed by these individuals emanate from one private university in Hong Kong may not be the shared views of university students across all other tertiary institutes, whether public or private. However, while this mixed-method research study combining both qualitative and quantitative data does not attempt to generalise its findings, it does provide indicative markers that may be transferable to other research contexts in the higher education paradigm - locally, or perhaps to a larger extent, globally.

As demonstrated by the current study, social networking sites such as Facebook can indeed be exploited to generate various educational affordances favorable to off-campus informal 
learning and course management activities in the context of higher education in Hong Kong. It is recommended that future research should take a larger sample and compare the LMS functions of Facebook with other existing commercial LMS tools such as Moodle, WebCT and Blackboard. The effectiveness of ICT in teaching and learning, with particular reference to Facebook, for young students as digital natives and mature students as digital immigrants, can also be investigated in future research endeavours.

\section{Notes}

Note 1. First developed by Mark Zuckerberg in 2004, Facebook is currently the most popular social networking site hosting over 829 million daily active users of all ages in different sectors across the globe, according to Facebook Reports Second Quarter 2014 Results. (https://www.facebook.com/)

\section{References}

Barkhuus, L. \& Tashiro, J. (2010). Student Socialization in the Age of Facebook. In Proceedings of the 28th International Conference on Human Factors in Computing Systems, CHI 2010, ACM, Atlanta. https://doi.org/10.1145/1753326.1753347

Bennett, S., Maton, K. \& Kervin, L. (2008). The 'digital natives' debate: A critical review of the evidence. British Journal of Educational Technology, 39(5), 775-786. https://doi.org/10.1111/j.1467-8535.2007.00793.x

Bloomfield. B., Latham. Y., \& Vurdubakis. T. (2010). Bodies, technologies and action possibilities: When is an affordance? Sociology, 44(3), 415-433. https://doi.org/10.1177/0038038510362469

Bosch, T. (2009). Using online social networking for teaching and learning: Facebook use at the University of Cape Town. Communication, 35(2), 185-200. https://doi.org/10.1080/02500160903250648

Cain, J. (2008). Online social networking issues within academia and pharmacy education. American Journal of Pharmaceutical Education, 72(1), 1-7. https://doi.org/10.5688/aj720110

Copola, P., Lomuscio, R., Mizzaro, S. \& Nazzi, E. (2008). Mobile \& Web 2.0 services intergration for cultural heritage. Retrieved on $2^{\text {nd }}$ September, 2014, from http://km.aifb.unikalrsruhede/ews/swkm2008/coppola-etal.pdf.

Dohn, B. N. (2009). Web 2.0: Inherent tensions and evident challenges for education. International Journal of Computer-Supported Collaborative Learning, 4, 343-363. https://doi.org/10.1007/s11412-009-9066-8

Gibson, J. (1979). The Ecological Approach to Visual Perception. New Jersey: Lawrence Earlbaum.

Jackson, C. (2011). Your students love social media ... and so can you. Teaching Tolerance, $39,38-41$.

Jimoyiannis, A., Tsiotakis, P., Roussinos, D. and Siorenta, A. (2012). Preparing teachers to 
integrate Web 2.0 in school practice: toward a framework for Pedagogy 2.0. Australasian Journal of Educational Technology, 29(2), 248-267. https://doi.org/10.14742/ajet.157

Jones, C, Ramanau, R, Cross, S. \& Healing, G. (2010). Net generation or Digital Natives: Is there a distinct new generation entering university? Computers and Education, 54(3), 722-732. https://doi.org/10.1016/j.compedu.2009.09.022

Junco, R. (2012). Too much face and not enough books: The relationship between multiple indices of Facebook use and academic performance. Computers in Human Behavior, 28, 187-198. https://doi.org/10.1016/j.chb.2011.08.026

Kosik, A. (2007). The implications of Facebook. Sharing the Commonwealth: Critical Issues in Higher Education, 9-10.

Krishnamurthy, B. \& Cormode, G. (2008). Key differences between Web 1.0 and Web 2.0. First Monday, 13(6).

Madge, C., et al. (2009). Facebook, social integration and informal learning at university: It is more for socialising and talking to friends about work than for actually doing work. Learning, Media and Technology, 34(2), 141-155. https://doi.org/10.1080/17439880902923606

Matias, A. \& Wolf, D. (2013). Engaging Students in Online Courses through the Use of Mobile Technology, in Wankel, L. \& Blessinger, P. (ed.) Increasing Student Engagement and Retention Using Mobile Applications: Smartphones, Skype and Texting Technologies (Cutting-edge Technologies in Higher Education, Volume 6), Emerald Group Publishing Limited. 115-142. https://doi.org/10.1108/S2044-9968(2013)000006D007

McLoughlin, C. \& Lee, M. J. W. (2008). Future learning landscapes: Transforming pedagogy through social software. Innovate: Journal of Online Education, 4(5).

Mehdinezhad, V. (2011). First year students' engagement at the university. International Online Journal of Educational Sciences, 3(1), 47-66.

Norman, D.A. (1999). Affordance, conventions, and design. Interactions, 6(3), 38-42. https://doi.org/10.1145/301153.301168

O'Reilly, T (2005). What is Web 2.0: Design Patterns and Business Models for the Next generation of Software. Retrieved on $2^{\text {nd }}$ September, 2014, from www.oreillynet.com/pub/a/oreilly/tim/news/2005/09/30/what-is-web-20.html.

Schwier, R. (2010). Focusing educational technology research on informal learning environments. Contemporary Educational Technology, 1(1), 90-92. https://doi.org/10.30935/cedtech/5965

Selwyn, N. (2007). Screw Blackboard . . . do it on Facebook: an investigation of students' educational use of Facebook. Proceedings from the Poke 1.0 Facebook Social Research Symposium. London. 1-23.

Stutzman, F. (2008). The vibrancy of online social space. In B. Rigby, Mobilizing generation 2.0: A practical guide to using web 2.0 technologies to recruit, engage \& activate youth. New 
York: Jossey-Bass.

Tomai, M., Rosa, V., Mebane, M., D’Acunti, A., Benedetti, M., \& Francescato, D. (2010). Virtual communities in schools as tools to promote social capital with high school students. Computers \& Education, 54, 265-274. https://doi.org/10.1016/j.compedu.2009.08.009

Treem, J. \& Leonardi, P. M. (2012). Social media use in organizations: exploring the affordances of visibility, editability, persistence and association. Communication Yearbook, 36. https://doi.org/10.2139/ssrn.2129853

Vivian, R. (2011). University students' informal learning practices using Facebook: help or hindrance? Communications in Computer and Information Science, 177, 254-267. https://doi.org/10.1007/978-3-642-22383-9_21

Vivian, R. \& Barnes, A. (2010). Social networking: from living technology to learning technology? Curriculum, Technology \& Transformation for an Unknown Future: Proceedings of the ASCILITE 2010, 1007-1019.

Waycott, J. \& Kenndy, G. (2009). Mobile and Web 2.0 technologies in undergraduate science: situating learning in everyday experience. In: Atkinson, R. \& McBeath, C. (Eds.), Same Places, Different Spaces. Proceedings of the Australasian Society for Computers in Learning in Tertiary Education 2009, Ascilite, Auckland. 1085-1095.

Wodzicki, K., Schwämmlein, E., \& Moskaliuk, J. (2012). Actually, I wanted to learn: Study-related knowledge exchange on social networking sites. Internet and Higher Education, 15, 9-14. https://doi.org/10.1016/j.iheduc.2011.05.008 